\title{
ABSENCE AND THE PHYSICAL CONDITIONS OF WORK
}

\author{
BY \\ R. D. SHEPHERD AND J. WALKER \\ From the Medical Research Council's Industrial Psychology Research Group, University College, London
}

(RECEIVED FOR PUBLICATION MARCH 12, 1957)

The early studies of the Health of Munition Workers Committee and of the Industrial Fatigue Research Board clearly demonstrated the effects of conditions of work on lost time. Loveday (1917) showed that when hours of work were long absence increased and that this was particularly marked on heavy work. Vernon (1920) compared the sickness absence of men on different occupations in the iron and steel industry and found that men employed on hot and heavy jobs experienced more sickness absence than those in other occupations. Vernon and Bedford (1928) demonstrated a relationship between atmospheric conditions in coal-mines and miners' absence. Recent research has been largely concerned with the effects of social and economic factors on absence. For instance, studies have dealt with morale (Behrend, 1951), size of undertaking (Acton Society Trust, 1953), and wage level and family responsibilities (Shepherd and Walker, 1956). However, the relative importance of these factors can only be assessed after the effects of the physical conditions on absence have been determined. It therefore seemed desirable to re-examine the relation between absence and the physical conditions of work. This paper gives the results of studies in an engineering firm and two iron and steel works where, on the whole, the conditions have improved markedly and bear little resemblance to those described in the earlier reports.

The iron and steel works were large plants employing about 4,000 and 7,000 male workers, excluding staff employees. All the processes which go to make steel products such as strip, plate, or sections, were carried out on each site. The main departments included ore preparation plants, sinter plants, coke ovens, blast furnaces, steel melting shops, and rolling mills. Most of the departments had been built or reconstructed since 1930, and many of them since the war. The working conditions were probably representative of other large undertakings in the industry. The engineering works contained a foundry and a forge in addition to three heavy engineering departments.

\section{Sources of Data}

The required information was copied from the firms' records. Such details as a man's age, length of service, and job were taken from the personnel cards; wages and income tax code number (an approximate index of family responsibilities) were extracted from the wages cards. The absences were obtained for 1952 from the absence record cards where these were maintained, and wherever possible their reliability was checked against samples of clock cards. In one of the steel firms which did not generally keep separate absence records the information was obtained from the wages cards. These were weekly records and it was not possible to determine the exact number of short-term absences although the amount of lost time was stated accurately. In one department the information had to be collected directly from the clock cards. The reasons for absence and other data, such as a list of the registered disabled persons, were recorded when they were available.

\section{Assessment of Conditions}

The multiplicity of jobs in the works made it impracticable for the investigators to attempt an objective measurement of the conditions of work. The assessment of conditions was therefore obtained from the managers and foremen who were asked to rate and rank the jobs according to the conditions which were associated with them. This was done for 296 jobs which included different and similar occupations; the latter were in different departments. The manager or foreman was given a number of cards on each of which was written the name of one of the principal jobs in his department and he arranged the jobs in order from the heaviest to the lightest. He was then given the following rating scales:- 
Physical Heaviness. - 1, Very heavy work; 2, heavy work; 3, medium heavy work; 4, medium; 5 , medium light work; 6 , light work; 7 , very light work.

Continuity of Working. -1 , continuous working; 2 , some pauses; 3 , many pauses.

Temperature. -1 , hot; 2 , some heat; 3 , normal.

Dust.-1, very dusty; 2 , fairly dusty; 3 , little dust. Fumes.-Yes or No.

The investigator read out the name of the job and the rater selected the appropriate categories on the scales. The judges were often in doubt how to rate occupations where the men were exposed to one of the conditions, particularly heat, for short periods during a shift. They were therefore asked to make the ratings refer to periods when the operators were working at the job and the assessment of the continuity of working would indicate if the men were exposed continually or intermittently to the condition. Wherever possible the ratings and rankings were obtained from more than one person and the judges were encouraged to discuss any features of the work which were unusual.

Each manager and foreman made assessments of the jobs in his own department and their reliability appeared to be satisfactory within departments. In 11 departments the coefficients of concordance (Kendall, 1948) between judges ranking jobs according to heaviness ranged from 0.55 to 0.94 with a median score of 0.87 . All the scores were statistically significant at the $1 \%$ level. The ratings on the sevenpoint scale for the heaviness of the jobs were transformed into rank order for each department, when the number of tied cases was not too great. The rank correlation ( $\mathrm{Tau}_{\mathrm{b}}$ ) was calculated when there were two judges and the coefficient of concordance when there were more than two judges. The coefficient in one department was significant at the $2 \%$ level and the remainder at the $1 \%$ level. These results show that there was good agreement between the judges who assessed the same jobs, although they did not measure the validity of the judgments against any objective standard. There were discrepancies in the ratings between departments; for example, crane driving in a department where the work was mainly light was rated as heavier than in a department where the work was predominantly heavy. This illustrates the effect of contrast. A light job was judged to be lighter by the supervisors when it was considered against a background of heavy jobs than when it was placed against other light jobs. Difficulties of this kind are usual when using rating techniques, but the conditions of work were observed and it seemed unlikely that these errors were sufficient to invalidate the grouping of jobs into the three categories : heavy, medium heavy, or light.

\section{Selection of the Men}

In the iron and steel works absence records were collected for all the men who were on jobs with arduous conditions and had been employed throughout the whole of 1952. A sample of one in four was selected from the men on other jobs. In the engineering works the same procedure was followed except that records were collected for all the men on the main production jobs. In this study some large groups were excluded from the samples, such as daymen employed on maintenance work as they often worked for long periods of overtime, particularly at the weekends and they were compensated by a day off during the week. It proved impossible to distinguish leave of this type from absence which was due to other reasons. General labourers were omitted from the sample, because labouring jobs were so varied as to make the rating of conditions unreliable. The registered disabled workers were also excluded.

\section{Shift Systems}

The men were employed on different shift systems with varied hours of work. The three main shift systems were:-

(1) Continuous 21-Shift Cycle.-The departments were manned continuously for 21 shifts a week throughout the year. The men worked seven shifts in succession followed by a rest period, after which they changed shifts. The sequence of change was from mornings to nights to afternoons. Over a seven-week period the hours of work averaged 48 per week in six eight-hour shifts, although some departments began to change to a 44-hour week towards the end of 1952. One department was on a discontinuous 19-shift cycle, but as the weekly hours of work and the annual planned shifts on both systems were the same, they are considered together.

(2) Discontinuous 17-Shift Cycle.-The departments were manned for 17 shifts a week from 10 p.m. on Sunday until 1 p.m. on Saturday. The men worked six morning, five afternoon, and six night shifts and changed shifts weekly in this sequence. Over a three-week period the weekly hours of work averaged 45. Two of the departments worked short time throughout part of the period and this would presumably have some effect on absence.

(3) Day Shift.-The day shifts divide into (a) a 44-hour four-day week, and (b) a 48-hour five-anda-half day week. 
Calculation of Absences

For the purpose of this study an absence has been defined as an occasion on which a man was away from work when it was planned that he would attend, and on which he lost one shift or more than one shift consecutively. Thus, if a man on the fiveday week was absent on Thursday and returned to work on Friday and was then absent on the following Monday to Thursday inclusive, he would have two absences, one of one shift and one of four shifts. If he was absent on Thursday and returned to work on the following Thursday, he would have one absence of five shifts. A whole shift has been taken as the unit of attendance and absence. On the 48-hour five-and-a-half-day week the half shifts worked on Saturday mornings have been counted as whole shifts. Similarly, all half shifts lost on Saturday morning and the few others which occurred during the week have been counted as whole shifts. Absence due to late arrival or early departure has been disregarded unless it amounted to a half shift. On this basis the absence of men working on the different shift systems has been combined. The main indices of absence used in the tables are the lost time and incidence rates which take account of the shifts lost and the number of absences respectively and express them as a percentage of the possible shifts:-

$$
\text { Percentage shifts lost }=\frac{\text { Shifts lost } \times 100}{\text { Possible Shifts }}
$$

Percentage incidence of absence $=\frac{\text { No. of Absences } \times 100}{\text { Possible Shifts }}$

Shifts lost after an absence of three months have been omitted and the number of possible shifts adjusted accordingly.

The number of possible shifts in the year ranged from 246 for a man on the five-day week to 299 on the 21-shift cycle. It has been pointed out (Buzzard, 1954) that absence rates are dependent to some extent on the number of planned shifts. Whenever the data allowed, the relation between absence and conditions of work was examined for the men on the separate shift systems to ensure that any results were not due to this variation in planned shifts.

\section{Results}

Age.-Table 1 shows the absence rates of the men in the sample grouped according to age. The numbers of men in the youngest and oldest age groups were too small to provide reliable rates and their absence has been combined with the adjacent groups. Absence is lowest among the men of 35 to 44 years and is greater in the younger and older age groups. The increase among the older men is more marked for the lost time rates than the incidence rates. In
TABLE 1

THE ABSENCE RATES OF THE MEN BY AGE

\begin{tabular}{c|c|c|c|c|c|c|c}
\hline Age & $<25$ & $25-34$ & $35-44$ & $45-54$ & $55-64$ & $>64$ & Total \\
\hline No. of men & 56 & 366 & 442 & 428 & 201 & 33 & 1,526 \\
\hline $\begin{array}{c}\text { \% Shifts lost } \\
\text { Incidence of } \\
\text { absence }\end{array}$ & 4.13 & 3.15 & 4.02 & 6.02 & 4.09 \\
\hline
\end{tabular}

the following analyses the men have been separated into those who were under and those who were over 45 years old in order to permit further division according to the conditions of work.

Temperature.-Mainly furnacemen were exposed to high temperatures, and included men who worked on melting shop platforms, on the front side of blastfurnaces, and in the rolling mills, particularly on the soaking pits or other furnaces. The forge in the engineering works had puddling and reheating furnaces with attendant operations which were hot. Exposure was usually to radiant heat in an atmosphere of low humidity, and was nearly always intermittent. Vernon (1920) demonstrated that similar conditions in a more extreme form affected the incidence of sickness, especially chills. Table 2 shows the absence rates of men in both age-groups who worked on jobs where the exposure to temperature differed. There was no evidence that absence increased on hot work, in fact there was a small

TABLE 2

ABSENCE RATES OF MEN ON WORK WITH DIFFERING EXPOSURE TO TEMPERATURE

\begin{tabular}{c|c|c|c}
\hline Type of Work & Hot Work & Some Heat & No Heat \\
\cline { 2 - 3 } Men under 45 years old & & & \\
No. of men & 204 & 251 & 409 \\
$\%$ Shifts lost & 3.10 & 3.61 & 3.89 \\
$\%$ Incidence of absence & 1.38 & 1.56 & 1.80 \\
\hline Men over 45 years old & & & \\
No. of men & 181 & 207 & 274 \\
$\%$ Shifts lost & 4.93 & 3.74 & 5.29 \\
$\%$ Incidence of absence & 1.70 & 1.55 & 1.88 \\
\hline
\end{tabular}

and irregular decrease in the absence rates with increasing exposure to heat. The trends were similar when absence on the separate shift systems was examined. The reasons for this unexpected finding are unknown. The results may reflect a high degree of selection of the men, including that afforded by medical supervision. Also, the effects of radiant heat differed between summer and winter. During the latter the heat source may have added to the comfort of working on some jobs. These questions will be considered in the discussion.

Continuity of Working.-There was wide variation in the continuity of working. In the iron and steel firms there were some occupations where the operators had little work to do for periods when the 
materials were in process, for example, in the blastfurnaces and steel melting shops. In one department the men, who made up the "frontside teams" on the blast-furnaces, were required to tap the furnaces every six hours. The manager estimated that the working time involved in the quite strenuous task of tapping and clearing up afterwards averaged four hours in an eight-hour shift. In contrast, the man who controlled the passage of ingots through a cogging mill, the first of the rolling processes, was on a task which demanded continual vigilance. He was seated in a " pulpit" set above the mill and operated the controls continuously unless there was a breakdown, a shortage of ingots, or the mill was stopped for maintenance.

In the engineering firm most of the men worked continuously throughout the shift, but each man or small groups of men usually had some control over the pace of work and its distribution over the shift. This was unlike the work of the blast-furnacemen referred to above. Both the continuity and pace of work may be determined by the type of work, or by other workers, or by the individual operator, but no attempt has been made to classify the operations on this basis.

Table 3 shows the absence rates of men on jobs where the work was assessed by the managers and foremen as continuous or having some and many pauses respectively. There appears to be no consistent relationship between absence and the continuity of working, although in the over- 45

TABLE 3

ABSENCE RATES OF MEN ON JOBS WITH DIFFERING CONTINUITY OF WORKING

\begin{tabular}{|c|c|c|c|}
\hline Type of Work & $\underset{\text { Work }}{\text { Continuous }}$ & $\begin{array}{c}\text { Some } \\
\text { Pauses }\end{array}$ & $\begin{array}{l}\text { Many } \\
\text { Pauses }\end{array}$ \\
\hline $\begin{array}{l}\text { Men under } 45 \text { years old } \\
\text { No. of men } \\
\% \text { Shifts lost } \\
\% \text { Incidence of absence }\end{array}$ & $\begin{array}{l}357 \\
3.85 \\
1.53\end{array}$ & $\begin{array}{l}373 \\
3.45 \\
1.65\end{array}$ & $\begin{array}{l}134 \\
3.47 \\
1.80\end{array}$ \\
\hline $\begin{array}{l}\text { Men over } 45 \text { years old } \\
\text { No. of men } \\
\% \text { Shifts lost } \\
\% \text { Incidence of absence }\end{array}$ & $\begin{array}{l}211 \\
5.94 \\
1.98\end{array}$ & $\begin{array}{l}257 \\
4 \cdot 44 \\
1 \cdot 54\end{array}$ & $\begin{array}{l}194 \\
3.74 \\
1.69\end{array}$ \\
\hline
\end{tabular}

age group there is an association with shifts lost, men on continuous work having more absence.

Dust and Fumes.-When rating the jobs the managers and foremen were asked to state whether fumes were present or not, and whether the working conditions were dusty, moderately dusty, or free from dust. These conditions were less common in the engineering works than in the iron and steel firms. In the latter, men who experienced fumes worked mainly on furnaces or in the coke ovens and coke oven by-product plant. Dusty conditions were frequent in departments engaged on the initial stages of manufacture, and included exposure to particles of iron ore in the ore preparation and sinter plants and dust from coal and coke in the coke ovens. There were small groups elsewhere who experienced dust, such as the men who handled lime in a melting shop.

The number of workers exposed to one type of dust or fumes was too small for specific examination; but it has been possible to compare those on work where there were fumes and on work where there were no fumes, and within these two categories on work which was assessed as dusty or moderately dusty and that which was free from dust. The large group of workers on the 21- and 19-shift cycles in one firm was selected for analysis. The jobs of nearly all the men had been rated for fumes and dust and Table 4 compares the absence rates of those, under and over 45, who were and were not exposed to these conditions. If the extremes are considered, the absence rate of the younger men who were exposed to both dust and fumes was 2.92 and for those who were exposed to neither the rate was 3.45; for the older men the rates were 4.57 and 4.14 respectively. However, the men who were exposed to fumes alone or dust alone had higher absence rates. The results are difficult to interpret, but the evidence does not suggest that these conditions had any general effect on absence behaviour.

TABLE 4

ABSENCE RATES OF MEN EXPOSED AND NOT EXPOSED TO FUMES AND DUST

\begin{tabular}{l|c|c|c|c}
\hline \multirow{2}{*}{ Type of Work } & \multicolumn{2}{|c|}{ Fumes } & \multicolumn{2}{c}{ No Fumes } \\
\cline { 2 - 5 } & Dust & No Dust & Dust & No Dust \\
\hline Men under 45 years old & & & & \\
No. of men & 67 & 45 & 86 & 32 \\
$\%$ Shifts lost & 2.92 & 3.78 & 3.43 & 3.45 \\
\% Incidence of absence & 1.25 & 1.57 & 1.38 & 0.97 \\
\hline Men over 45 years old & & & & \\
No. of men & 39 & 48 & 61 & 23 \\
$\%$ Shifts lost & 4.57 & 5.30 & 5.14 & 4.14 \\
$\%$ Incidence of absence & 1.11 & 1.90 & 1.66 & 1.42 \\
\hline
\end{tabular}

Heaviness of Work.-The physical heaviness of each job was rated on the seven-point scale described above. This was reduced to a threefold classification, and Table 5 shows the absence rates of men on work rated as heavy, medium heavy, and light. There is an increase in the amount and incidence of absence as the work becomes heavier, and the trends are consistent in both age groups. The nature of this association will be examined later.

The next step was to consider the effects of interaction between different conditions. Although a particular condition might not influence absence from work, if two or more were present at the same time they could do so. For example, there is the expectation that continuous heavy work carried out 
TABLE 5

ABSENCE RATES OF MEN ON JOBS WITH DIFFERING HEAVINESS OF WORK

\begin{tabular}{|c|c|c|c|}
\hline Type of Work & $\begin{array}{l}\text { Heavy } \\
\text { Work }\end{array}$ & $\begin{array}{c}\text { Medium } \\
\text { Heavy }\end{array}$ & $\begin{array}{l}\text { Light } \\
\text { Work }\end{array}$ \\
\hline $\begin{array}{l}\text { Men under } 45 \text { years old } \\
\text { No. of men } \\
\% \text { Shifts lost } \\
\% \text { Incidence of absence }\end{array}$ & $\begin{array}{l}242 \\
4 \cdot 93 \\
2 \cdot 21\end{array}$ & $\begin{array}{l}315 \\
3.61 \\
1.61\end{array}$ & $\begin{array}{l}307 \\
2 \cdot 59 \\
1.18\end{array}$ \\
\hline $\begin{array}{l}\text { Men over } 45 \text { years old } \\
\text { No. of men } \\
\% \text { Shifts lost } \\
\% \text { Incidence of absence }\end{array}$ & $\begin{array}{l}266 \\
5 \cdot 03 \\
2 \cdot 08\end{array}$ & $\begin{array}{l}191 \\
4 \cdot 85 \\
1 \cdot 77\end{array}$ & $\begin{array}{l}205 \\
4 \cdot 10 \\
1 \cdot 21\end{array}$ \\
\hline
\end{tabular}

in a hot environment would be associated with high absence rates; but owing to the small numbers of men it was only possible to examine the effects of two factors at a time. One comparison of this kind was found to show a relationship. Table 6 and
Fig. 1 give the absence rates of men on jobs where the heaviness and continuity of working differed.

The results show (Fig. 1) that when the work is continuous or has some pauses in activity, absence rates decrease as the work also becomes lighter. For example, the lost time rates of the younger men on continuous work were $6.77,3.74$, and 2.49 for those on heavy, medium heavy, and light work respectively. This trend is not sustained on work with many pauses in activity. Table 6 also shows that on heavy work absence decreases as there are more pauses in activity. For example, the lost time rates of the younger men on heavy work were 6.77, $4 \cdot 36$, and 3.64 for those on continuous work or work with some and many pauses respectively. On medium heavy and light work these trends are not sustained. Table 6 further illustrates the point that

PER CENT FIG. 1.-Absence rates of men on jobs where the heaviness and continuity of working differed.

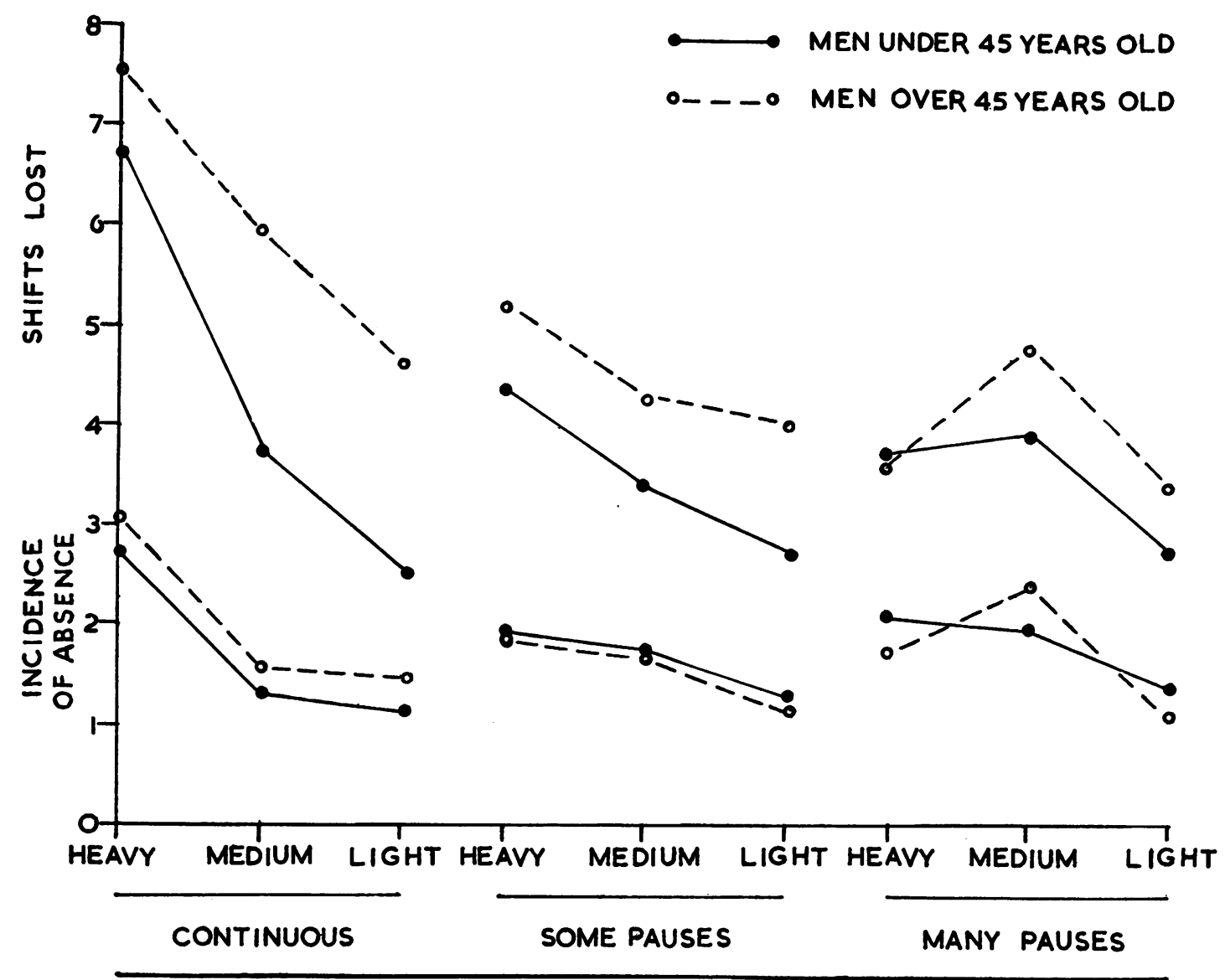

TYPE OF WORK 
TABLE 6

ABSENCE RATES OF MEN ON JOBS WITH DIFFERING HEAVINESS AND CONTINUITY OF WORKING

\begin{tabular}{|c|c|c|c|c|c|c|c|c|c|}
\hline \multirow{2}{*}{ Type of Work } & \multicolumn{3}{|c|}{$\%$ Shifts Lost } & \multicolumn{3}{|c|}{$\%$ Incidence of Absence } & \multicolumn{3}{|c|}{ No. of Men } \\
\hline & $\begin{array}{l}\text { Heavy } \\
\text { Work }\end{array}$ & $\underset{\text { Heavy }}{\text { Medium }}$ & $\begin{array}{l}\text { Light } \\
\text { Work }\end{array}$ & $\begin{array}{l}\text { Heavy } \\
\text { Work }\end{array}$ & $\underset{\text { Heavy }}{\text { Medium }}$ & $\begin{array}{l}\text { Light } \\
\text { Work }\end{array}$ & $\begin{array}{l}\text { Heavy } \\
\text { Work }\end{array}$ & $\underset{\text { Meavy }}{\text { Meaum }}$ & $\begin{array}{l}\text { Light } \\
\text { Work }\end{array}$ \\
\hline $\begin{array}{l}\text { Men under } 45 \text { years old } \\
\text { Continuous work } \\
\text { Some pauses } \\
\text { Many pauses }\end{array}$ & $\begin{array}{l}6 \cdot 77 \\
4 \cdot 36 \\
3 \cdot 64\end{array}$ & $\begin{array}{l}3 \cdot 74 \\
3 \cdot 36 \\
3 \cdot 86\end{array}$ & $\begin{array}{l}2 \cdot 49 \\
2 \cdot 67 \\
2 \cdot 70\end{array}$ & $\begin{array}{l}2 \cdot 76 \\
1.96 \\
2 \cdot 02\end{array}$ & $\begin{array}{l}1.29 \\
1.78 \\
1.95\end{array}$ & $\begin{array}{l}1 \cdot 12 \\
1.22 \\
1 \cdot 30\end{array}$ & $\begin{array}{r}76 \\
121 \\
45\end{array}$ & $\begin{array}{r}136 \\
127 \\
52\end{array}$ & $\begin{array}{r}145 \\
125 \\
37\end{array}$ \\
\hline $\begin{array}{l}\text { Men over } 45 \text { years old } \\
\text { Continuous work } \\
\text { Some pauses } \\
\text { Many pauses }\end{array}$ & $\begin{array}{l}7 \cdot 55 \\
5 \cdot 19 \\
3 \cdot 51\end{array}$ & $\begin{array}{l}5 \cdot 99 \\
4 \cdot 22 \\
4 \cdot 74\end{array}$ & $\begin{array}{l}4 \cdot 60 \\
3 \cdot 94 \\
3 \cdot 39\end{array}$ & $\begin{array}{l}3.04 \\
1.87 \\
1.68\end{array}$ & $\begin{array}{l}1.54 \\
1.64 \\
2 \cdot 36\end{array}$ & $\begin{array}{l}1.42 \\
1.10 \\
1.04\end{array}$ & $\begin{array}{r}71 \\
82 \\
113\end{array}$ & $\begin{array}{l}58 \\
93 \\
40\end{array}$ & $\begin{array}{l}82 \\
82 \\
41\end{array}$ \\
\hline
\end{tabular}

continuity of working may affect the absence of older men. On continuous work, the older men had a higher incidence of absence. If shifts lost are considered for the over-45 years age group there appears to be a relation between continuity of working and absence for men in all " heaviness" categories.

Men are sometimes compensated for unfavourable conditions of work by extra payment and, although this is often small in relation to the total wage, it was necessary to ensure that there was no systematic association between pay and the heaviness or continuity of working which could confound the results. There was no relation between wage and continuity of working, but the average earnings for a full week's attendance at work of men on heavy, medium, and light jobs were 221, 199, and 206 shillings respectively. Thus, the men on heavy work received higher pay than those in the other groups. However, the relation was not systematic, and there was also no correlation between the absence rates of the groups in Table 6 and their average earnings.

The physical heaviness of the work was the only condition which showed a consistent relationship with the amount and incidence of absence in both age groups. It is important to demonstrate that the trend was general and was not attributable to a limited number of workers, for instance, the men in one firm. Accordingly, six groups were selected which differentiated the sample by shift system and/or works. Table 7 shows the numbers and percentages of men in the heaviness categories who experienced different numbers of absences in the year. Here individual differences in absence behaviour are being considered rather than group averages. The totals show that $30 \%$ of the men on heavy work and only $13 \%$ of those on light work had more than six absences in the year; conversely, $47 \%$ of the men on heavy work and $64 \%$ of the men on light work had 0-3 absences. The absences of men on medium heavy work fell between these two extremes. The difference is statistically significant.*

When the absences in each group are examined the results show that in all cases a greater proportion of the men on heavy work as compared with light work had more than six absences in the year, and

\footnotetext{
*In groups $A, B$, and $F$ and the total the expected trends are regular. Chi-squared is statistically significant at the $1 \cdot 0,0 \cdot 1,5 \cdot 0$, and $0.1 \%$ levels respectively. In groups $C, D$, and $E$ the expected trends are not consistent, and the $x^{2}$ test was not applied.
}

NUMBERS OF MEN ON HEAVY, MEDIUM, AND LIGHT WORK WITH VARYING NUMBERS OF ABSENCES IN THE YEAR

\begin{tabular}{|c|c|c|c|c|c|c|c|c|c|c|c|c|c|c|c|c|c|c|c|c|c|}
\hline Groups & \multirow{2}{*}{\multicolumn{3}{|c|}{$\frac{\text { A }}{\text { Steel Works }}$}} & \multirow{2}{*}{\multicolumn{3}{|c|}{$\frac{\text { B }}{\text { Steel Works }}$}} & \multirow{2}{*}{\multicolumn{3}{|c|}{$\frac{\mathrm{C}}{\text { Engineering }}$}} & \multirow{2}{*}{\multicolumn{3}{|c|}{$\frac{\text { D }}{\text { Both }}$}} & \multirow{2}{*}{\multicolumn{3}{|c|}{$\frac{\text { E }}{\text { Both }}$}} & \multirow{2}{*}{\multicolumn{3}{|c|}{$\frac{F}{\text { Engineering }}$}} & \multicolumn{3}{|c|}{ Total } \\
\hline Works & & & & & & & & & & & & & & & & & & & & & \\
\hline Shift System & \multicolumn{3}{|c|}{$21+19$ Shifts } & \multicolumn{3}{|c|}{21 Shifts } & \multicolumn{3}{|c|}{ 5-Day Week } & \multicolumn{3}{|c|}{$\overline{5 \frac{1}{2} \text {-Day Week }}$} & \multicolumn{3}{|c|}{17 Shifts } & \multicolumn{3}{|c|}{$\overline{\text { Miscellaneous }}$} & \multicolumn{3}{|c|}{ Miscellaneous } \\
\hline Type of Work & 胥 & 咅 & $\stackrel{\vec{s}}{.00}$ & 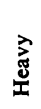 & 苞 & 壳 & 庶 & $\underset{\Sigma}{E}$ & 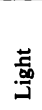 & 䄊 & 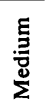 & 䒿 & 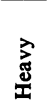 & 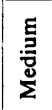 & 壱 & 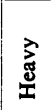 & 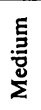 & 疍 & 庀 & $\underset{\Sigma}{E}$ & $\stackrel{5}{5}$ \\
\hline $\begin{array}{c}\text { Number of Men } \\
0-3 \text { Absences } \\
4-6, " \\
>6 \quad "\end{array}$ & $\begin{array}{l}51 \\
35 \\
27\end{array}$ & $\begin{array}{l}87 \\
38 \\
33\end{array}$ & $\begin{array}{l}91 \\
33 \\
11\end{array}$ & $\begin{array}{l}49 \\
21 \\
38\end{array}$ & $\begin{array}{l}42 \\
26 \\
14\end{array}$ & $\begin{array}{l}53 \\
12 \\
12\end{array}$ & $\begin{array}{l}60 \\
12 \\
18\end{array}$ & $\begin{array}{r}102 \\
27 \\
17\end{array}$ & $\begin{array}{l}70 \\
16 \\
17\end{array}$ & $\begin{array}{r}6 \\
3 \\
11\end{array}$ & $\begin{array}{r}9 \\
9 \\
30\end{array}$ & $\begin{array}{r}13 \\
10 \\
7\end{array}$ & $\begin{array}{l}40 \\
28 \\
12\end{array}$ & $\begin{array}{r}32 \\
9 \\
2\end{array}$ & $\begin{array}{l}89 \\
34 \\
16\end{array}$ & $\begin{array}{l}33 \\
16 \\
48\end{array}$ & $\begin{array}{r}10 \\
8 \\
11\end{array}$ & $\begin{array}{r}14 \\
9 \\
5\end{array}$ & $\begin{array}{l}239 \\
115 \\
154\end{array}$ & $\begin{array}{l}282 \\
117 \\
107\end{array}$ & $\begin{array}{r}330 \\
114 \\
68\end{array}$ \\
\hline $\begin{array}{l}\text { Percentage of Men } \\
0-3 \text { Absences } \\
46 \\
>6\end{array}$ & $\begin{array}{l}45 \\
31 \\
24\end{array}$ & $\begin{array}{l}55 \\
24 \\
21\end{array}$ & $\begin{array}{r}67 \\
24 \\
8\end{array}$ & $\begin{array}{l}45 \\
19 \\
35\end{array}$ & $\begin{array}{l}51 \\
32 \\
17\end{array}$ & $\begin{array}{l}69 \\
16 \\
16\end{array}$ & $\begin{array}{l}67 \\
13 \\
20\end{array}$ & $\begin{array}{l}70 \\
18 \\
12\end{array}$ & $\begin{array}{l}68 \\
16 \\
17\end{array}$ & $\begin{array}{l}30 \\
15 \\
55\end{array}$ & $\begin{array}{l}19 \\
19 \\
63\end{array}$ & $\begin{array}{l}43 \\
33 \\
23\end{array}$ & $\begin{array}{l}50 \\
35 \\
15\end{array}$ & $\begin{array}{r}74 \\
21 \\
5\end{array}$ & $\begin{array}{l}64 \\
24 \\
12\end{array}$ & $\begin{array}{l}34 \\
16 \\
49\end{array}$ & $\begin{array}{l}34 \\
28 \\
38\end{array}$ & $\begin{array}{l}50 \\
32 \\
18\end{array}$ & $\begin{array}{l}47 \\
23 \\
30\end{array}$ & $\begin{array}{l}56 \\
23 \\
21\end{array}$ & $\begin{array}{l}64 \\
22 \\
13\end{array}$ \\
\hline
\end{tabular}


a smaller proportion had none to three absences. However, the trends are regular and statistically significant in groups $\mathrm{A}, \mathrm{B}$, and $\mathrm{F}$, but not in groups $\mathrm{C}, \mathrm{D}$, and $\mathrm{E}$. Men in groups $\mathrm{A}, \mathrm{B}$, and $\mathrm{F}$ worked in the two steel firms and the engineering works respectively. The association between the heaviness of the work and absence was not, therefore, specific to one factory.

The higher absence of men on heavy work could be due to a greater amount of sickness. This was tested in two ways: first, by considering the distribution of absences of different lengths in the heaviness categories, and, secondly, by analysing the classification of absences. The former method was more widely applicable to the data, as the classification of absence was not available for some factory groups. In the records where the absences were classified with reasonable thoroughness it was found that most absences of four to nine days' duration and nearly all absences of $\mathbf{1 0}$ days or longer were due to certified sickness or injury. Absences of less than four days in length included nearly all the absences without permission, leave, uncertified sickness, and a few injuries.

The number of absences of different lengths and the days lost which were due to these were tabulated for each " heaviness" category. The calculated absence rates are shown in Table 8.
In the younger age group the incidence of absences of all lengths decreases as the work becomes lighter, although the trend is more noticeable for short absences than long absences. In the older age group the incidence of short absences also decreases but the number of long-term absences remains relatively constant. The lost time rates follow a similar pattern. A possible explanation for the discrepancy in absence behaviour between the older and younger men was that the unfit had ceased to work on heavy jobs and only those older workers who were best able to undertake arduous work remained. However, it is necessary to be cautious in making such interpretations as the number of men and the number of long-term absences were small.

The classification of absence into sickness and other categories was available for a large group of workers on the 21- and 19-shift cycles (Table 7, Group A). The reasons for absence were ascertained by the foremen and timekeepers as accurately as was possible. The number of absences in the year and the average number per man are shown in Table 9 for workers in the " heaviness" categories. The absences are grouped into those which were due to sickness and injury, and to "other reasons" (absence with or without permission and uncertified sickness).

TABLE 8

ABSENCE RATES DUE TO ABSENCES OF DIFFERENT LENGTHS OF MEN ON JOBS WITH DIFFERING HEAVINESS OF WORK

\begin{tabular}{|c|c|c|c|c|c|c|}
\hline \multirow[b]{2}{*}{ Length of Absence } & \multicolumn{3}{|c|}{ \% Shifts Lost } & \multicolumn{3}{|c|}{$\%$ Incidence of Absence } \\
\hline & $\begin{array}{l}\text { Heavy } \\
\text { Work }\end{array}$ & $\underset{\text { Medium }}{\text { Heavy }}$ & $\begin{array}{l}\text { Light } \\
\text { Work }\end{array}$ & $\begin{array}{l}\text { Heavy } \\
\text { Work }\end{array}$ & $\begin{array}{c}\text { Medium } \\
\text { Heavy }\end{array}$ & $\begin{array}{l}\text { Light } \\
\text { Work }\end{array}$ \\
\hline $\begin{array}{l}\text { Men under } 45 \text { years old } \\
1 \text { day } \\
2-4 \\
5-9 \\
>9 \\
\text { No. of Men }\end{array}$ & $\begin{array}{l}1.63 \\
0.94 \\
0.65 \\
1.70 \\
242\end{array}$ & $\begin{array}{l}1 \cdot 20 \\
0.63 \\
0.47 \\
1.30 \\
315\end{array}$ & $\begin{array}{l}0.89 \\
0.40 \\
0.45 \\
0.85 \\
307\end{array}$ & $\begin{array}{l}1.63 \\
0.39 \\
0 \cdot 11 \\
0.08 \\
-\end{array}$ & $\begin{array}{l}1.20 \\
0.27 \\
0.08 \\
0.06 \\
-\end{array}$ & $\begin{array}{l}0.89 \\
0.17 \\
0.07 \\
0.05 \\
-\end{array}$ \\
\hline $\begin{array}{l}\text { Men over } 45 \text { years old } \\
1 \text { day } \\
2-4 \\
5-9 \\
>9 \\
\text { No. of Men }\end{array}$ & $\begin{array}{l}1.52 \\
0.96 \\
0.52 \\
2.02 \\
266\end{array}$ & $\begin{array}{l}1 \cdot 33 \\
0 \cdot 63 \\
0 \cdot 50 \\
2 \cdot 38 \\
191\end{array}$ & $\begin{array}{l}0.83 \\
0.52 \\
0.53 \\
2.22 \\
205\end{array}$ & $\begin{array}{l}1.52 \\
0.39 \\
0.09 \\
0.08 \\
-\end{array}$ & $\begin{array}{l}1.33 \\
0.27 \\
0.08 \\
0.09 \\
-\end{array}$ & $\begin{array}{l}0.83 \\
0.21 \\
0.09 \\
0.09 \\
-\end{array}$ \\
\hline
\end{tabular}

TABLE 9

INCIDENCE OF ABSENCE DUE TO SICKNESS OR INJURY AND OTHER REASONS OF MEN ON JOBS WITH DIFFERING HEAVINESS OF WORK

\begin{tabular}{|c|c|c|c|c|c|c|}
\hline \multirow[b]{2}{*}{ Type of Work } & \multicolumn{3}{|c|}{ Men under 45 Years Old } & \multicolumn{3}{|c|}{ Men over 45 Years Old } \\
\hline & $\begin{array}{c}\text { Heavy } \\
\text { Work }\end{array}$ & $\begin{array}{c}\text { Medium } \\
\text { Heavy }\end{array}$ & $\begin{array}{l}\text { Light } \\
\text { Work }\end{array}$ & $\begin{array}{l}\text { Heavy } \\
\text { Work }\end{array}$ & $\begin{array}{c}\text { Medium } \\
\text { Heavy }\end{array}$ & $\begin{array}{l}\text { Light } \\
\text { Work }\end{array}$ \\
\hline No. of Men & 54 & 107 & 73 & 59 & 51 & 62 \\
\hline $\begin{array}{l}\text { Number of Absences } \\
\text { Sickness or Injury } \\
\text { Other Reasons }\end{array}$ & $\begin{array}{r}16 \\
242\end{array}$ & $\begin{array}{r}39 \\
406\end{array}$ & $\begin{array}{r}19 \\
194\end{array}$ & $\begin{array}{r}27 \\
305\end{array}$ & $\begin{array}{r}16 \\
242\end{array}$ & $\begin{array}{r}38 \\
174\end{array}$ \\
\hline $\begin{array}{l}\text { Number of Absences per Man } \\
\text { Sickness or Injury } \\
\text { Other Reasons }\end{array}$ & $\begin{array}{l}0.30 \\
4 \cdot 48\end{array}$ & $\begin{array}{l}0.36 \\
3.79\end{array}$ & $\begin{array}{l}0.26 \\
2.66\end{array}$ & $\begin{array}{l}0.46 \\
5 \cdot 17\end{array}$ & $\begin{array}{l}0.31 \\
4.75\end{array}$ & $\begin{array}{l}0.61 \\
2.81\end{array}$ \\
\hline
\end{tabular}


The table shows that there are fewer absences in the "other reasons" category as the work became lighter,* but there is no consistent relationship between the incidence of sickness absence and injury and the heaviness of the work.

\section{Discussion}

The results from this study showed that there was a relationship between absence and the heaviness of the work, as assessed by the managers and foremen. Among the younger men the number of absences of all lengths increased as the work became heavier, and all except the longer absences increased among the older men. Examination of the "reasons" for absence, as classified in one firm, showed no significant relationship between the incidence of sickness or injury and the heaviness of the work; the relationship was predominantly due to those absences classed under " other reasons". When the men were separated into their different factory groups and according to the shift systems they worked, the association was apparent in the three firms and on all shift systems, although it was statistically significant in some groups but not in others.

There was an interaction between the heaviness and continuity of working such that the men on continuous heavy work had high absence rates. It also appeared that the continuity of working affected the older men more than the younger.

Exposure to heat, as assessed by the managers and foremen, was associated with a decrease rather than an increase in absence rates. In one firm there was no evidence of a consistent relationship between absence and exposure to dust or fumes. These results do not exclude the possibility that on particular jobs the working conditions did affect absence, but the number of men on any single operation was too small to test this.

The findings must be evaluated in relation to other factors in the working situation, and among the most important of these was the selection and placement of the workers. If there was a tendency for less fit men to be transferred from work with adverse conditions then no association with absence was likely to emerge, but if there was a tendency for less fit workers to be placed on jobs with adverse conditions, then any trends would be exaggerated. There was evidence that both these selective processes existed, although they cannot be demonstrated quantitatively.

* For men in both age groups $x^{2}$ is significant at the $0.1 \%$ level. Chi-squared is applied on the assumption that the observations in each cell are independent, although this is not strictly correct when a man has more than one absence.
Each of the three works had medical officers who carried out a pre-employment examination of new entrants. Those who were unfit were not placed on the more arduous jobs, and others with specific complaints were excluded from particular occupations. In addition, men who returned from a long sickness absence were medically examined before resuming work. If they were unfit to work on their previous job they would be advised to ask for a transfer.

In the iron and steel works most production jobs were manned by small groups of workers. A new entrant to a department might be started as a shift labourer. Later he would be placed on the lowest ranked job on a production process and during his working life would be promoted until he was a senior operator. The heavier jobs were often of low rank in the promotion sequence and the men would work on them relatively early in their careers. In one department the example was given of a heavy job in the open air which had been transferred to a lower position in the promotion sequence so that it could be manned by a younger worker. In a few instances where conditions were severe, operators were provided with relief men; this happened with soaking pit crane drivers who were exposed to high temperatures.

It is probable that self-selection occurred, particularly in the engineering works where there was little opportunity for promotion and men usually stayed on the same job. It is difficult to demonstrate that men who are unsuited to a job fail to take it up, or that they start work and then leave, but there was some evidence for this. Younger men had an increasing frequency of long absences as the work became heavier, but this did not occur with older men and it was suggested that only the fittest of the latter remained on heavy work.

There appeared to be selective factors which were having the opposite effect. It was difficult to recruit labour for some of the most arduous or unpleasant work, and this was particularly noticeable on obsolescent jobs which were manned by men prone to have many absences. For instance, the forge in the engineering works contained many of the heaviest jobs observed. The conditions on the puddling furnaces and the hand rolling mill differed little from those which were described by Vernon (1920). Of the 11 puddlers, seven were over 50 years old, and furnaces were idle for want of labour. The lost-time rate in the forge was $8.14 \%$, which was the highest of any department. This illustration serves to show that on some of the heaviest jobs the labour employed was liable to have a high absence rate. However, on the whole the processes of selection reduced the probability that adverse work- 
ing conditions would have long-term effects on the health of the workers. The medical supervision of placement was probably an important influence in this respect.

\section{Conclusions}

In brief, then, the results from the investigation suggest that where arduous physical work is still practised men will have more absence than those employed on lighter work. In this study the trend was more pronounced for short absences than for long absences. These findings must be seen in relation to the pre-employment medical examination of the men, the transfer of men who were no longer physically suited to heavy work to other jobs, and the system of promotion in the iron and steel works which meant that many men worked on a variety of occupations throughout their careers and experienced varied conditions of work. In a few occupations selection was probably in the opposite direction and older men were working in conditions for which younger men would be better suited. It is difficult to describe the selective processes in industry or to assess their effects. It is probable that some, such as the movement of the unfit to easier work, are general factors, but others, such as the effects of promotion, are specific to an industry or to an individual firm. Belbin (1955) has given a detailed discussion of this question in relation to the proportion of older people on heavy work.

The continuity of working also appeared to be related to absence, although the result was less striking than with heavy work. Men in occupations which involved both continuous and heavy work had higher absence rates than workers on other jobs. Older men on continuous work lost more time than those who worked intermittently throughout the shift, but men under 45 years old were not affected in this way. Welford (1951) found that on work which was paced the proportion of older workers employed was less than on operations which were unpaced, and Richardson (1953) showed that older men tended to move from work where there was speed stress. Although all the occupations which involved continuous work were not paced the findings here tend to confirm the unsuitability of this type of work as age increases.

Absence statistics can demonstrate the association between the heaviness or continuity of working and absence, but they can reveal little about the causes of the association. These could include the direct effects of fatigue, a disinclination to attend when the work was arduous or uncomfortable, inability to tolerate heavy work when slightly " off colour" or convalescing, or differences in the selection of the men doing the work. Probably physical and psychological states contributed to the result, but it is not possible here to determine their relative importance.

Exposure to heat was associated with a decrease rather than an increase in absence rates, although the reasons for this were unknown. In the one firm where an analysis was made, exposure to dust and fumes was not related to absence, but owing to the few workers involved in the comparisons this cannot be considered as conclusive.

\section{Summary}

The absence records of selected samples of men employed in an engineering firm and two iron and steel works were examined to test for associations between the physical conditions of work and absence. The conditions of work were assessed by the managers and foremen using rating and ranking techniques. The physical heaviness, continuity of working, temperature, and exposure to dust and fumes which were associated with the occupations were assessed by these methods. There was a relationship between the physical heaviness of the work and absence. The continuity of working in combination with other factors was also associated with absence. There was no increase in absence with exposure to heat, dust, or fumes. The results are discussed in relation to the selective factors operating.

This work has been under the general direction of Dr. R. B. Buzzard and Mr. J. W. Whitfield to whom we are greatly indebted for help and advice. We are also grateful to our colleagues at University College, London, for valuable criticism. We wish to thank the members of the firms we visited for their cooperation, and we are especially grateful to the medical officers and labour managers.

\section{REFERENCES} Acton Society Trust (1953). Size and Morale. London.
Behrend, H. (1951). Absence under Full Employment. Studies in

Economics and Society. University of Birmingham.
Belbin, R. M. (1955). British Journal of Industrial. Medicine, 12, 309. Buzzard, R. B. (1954). British J. Soc., 5, 238.

Kendall, M. G. (1948). Rank Correlation Methods. Griffin, London. Kendall, M. G. (1948). Rank Correlation Methods. Griffin, London. Interim Report: Industrial Efficiency and Fatigue, p. 41. [Cd 8511]. H.M.S.O. London.

Richardson, I. M. (1953). British Journal of Industrial Medicine, $10,269$.

Shepherd, R. D. and Walker, J. (1956). Absence from Work in Relation to Level of Earnings and Family Responsibilities. Unpublished Report.

Vernon, H. M. (1920). Rep. industr. Fatig. Res. Bd., Lond., No. 5. H.M.S.O.

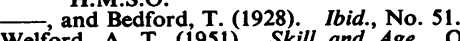

Welford, A. T. (195i). Skill and Age. Oxford University Press, London. 